\title{
Condições higiênicossanitárias de ovos comercializados em diferentes cidades do
}

\section{Brasil: uma revisão}

\author{
Hygienic and sanitary conditions of eggs marketed in different cities in Brazil: a review \\ Condiciones higiénicas y sanitarias de los huevos comercializados en diferentes ciudades de Brasil:
} una revisión

Recebido: 16/10/2021 | Revisado: 30/10/2021 | Aceito: 31/10/2021 | Publicado: 01/11/2021

Deise Fraga do Carmo

ORCID: https://orcid.org/0000-0001-7222-8707 Instituto Federal de Educação, Ciência e Tecnologia do Triângulo Mineiro, Brasil E-mail: deise.carmo@estudante.iftm.edu.br

Adriana Garcia de Freitas

ORCID: https://orcid.org/0000-0001-8288-9189

Instituto Federal de Educação, Ciência e Tecnologia do Triângulo Mineiro, Brasil E-mail: adrianagarcia@iftm.edu.br

\begin{abstract}
Resumo
No contexto da crise alimentícia que o Brasil vem sofrendo no ano de 2021, agravada cada vez mais pelo prolongamento da atual situação pandêmica, cada vez mais famílias substituíram gêneros alimentícios na sua dieta. As carnes, que já vinham sofrendo alta de preços ao longo dos últimos anos, são substituídas por outros tipos de fontes proteicas, principalmente os ovos. Os ovos são alimentos largamente comercializados no Brasil e bastante consumidos pela população em geral. São um alimento altamente nutritivo e que pode ser consumido com grande versatilidade. Contudo, ovos quando não manipulados e acondicionados de forma adequada, podem trazer riscos à saúde do consumidor. Microrganismos como Salmonella sp., Staphylococcus aureus e coliformes são grandes responsáveis por surtos de infecções e intoxicações gastrointestinais. Este estudo traz um levantamento dos principais artigos publicados nos últimos 6 anos, sobre as condições higiênicossanitarias de ovos comercializados em diferentes regiões do Brasil. Os artigos foram obtidos em pesquisas através de sites como SciELO e Google Acadêmico. Como resultado da pesquisa selecionou-se 14 artigos, entre os anos de 2015 a 2020, que estudaram o tema em diferentes cidades do Brasil. É possível notar que a qualidade dos ovos comercializados é bem diversificada e os estudos variam bastante entre as diferentes cidades do Brasil. Muitos artigos não abordam estudos microbiológicos, o que seria de extrema importância para determinar a qualidade dos ovos analisados.
\end{abstract}

Palavras-chave: Qualidade; Segurança alimentar; Condições higiênicossanitarias.

\begin{abstract}
In the context of the food crisis that Brazil has been suffering in the year 2021, increasingly aggravated by the extension of the current pandemic situation, more and more families have replaced foodstuffs in their diet. Meats, which had already been suffering high prices over the past few years, are replaced by other types of protein sources, especially eggs. Eggs are food widely traded in Brazil and widely consumed by the population in general. They are a highly nutritious food that can be consumed with great versatility. However, eggs when not handled and packaged properly, can pose risks to the consumer's health. Microorganisms such as Salmonella sp., Staphylococcus aureus and coliforms are largely responsible for outbreaks of infections and gastrointestinal poisoning. This study brings a survey of the main articles published in the last 6 years, on the hygienic and sanitary conditions of eggs sold in different regions of Brazil. The articles were obtained from research through sites such as SciELO and Google Scholar. As a result of the research, 14 articles were selected, between the years 2015 to 2020, which studied the topic in different cities in Brazil. It is possible to notice that the quality of the commercialized eggs is very diverse and the studies vary a lot between different cities in Brazil. Many articles do not address microbiological studies, which would be extremely important to determine the quality of the eggs analyzed.
\end{abstract}

Keywords: Quality; Food safety; Hygienic-sanitary conditions.

\section{Resumen}

En el contexto de la crisis alimentaria que viene sufriendo Brasil en el año 2021, cada vez más agravada por la extensión de la actual situación pandémica, cada vez más familias han reemplazado los alimentos en su dieta. Las carnes, que ya habían estado sufriendo altos precios en los últimos años, son reemplazadas por otro tipo de fuentes de proteínas, especialmente huevos. Los huevos son un alimento ampliamente comercializado en Brasil y ampliamente consumido 
por la población en general. Son un alimento altamente nutritivo que se puede consumir con gran versatilidad. Sin embargo, cuando no se manipulan y envasan correctamente, los huevos pueden presentar riesgos para la salud del consumidor. Los microorganismos como Salmonella sp., Staphylococcus aureus y coliformes son en gran parte responsables de los brotes de infecciones y la intoxicación gastrointestinal. Este estudio trae un relevamiento de los principales artículos publicados en los últimos 6 años, sobre las condiciones higiénicas y sanitarias de los huevos vendidos en diferentes regiones de Brasil. Los artículos se obtuvieron de investigaciones a través de sitios como SciELO y Google Scholar. Como resultado de la investigación, se seleccionaron 14 artículos, entre los años 2015 a 2020 , que estudiaron el tema en diferentes ciudades de Brasil. Se puede notar que la calidad de los huevos comercializados es muy diversa y los estudios varían mucho entre diferentes ciudades de Brasil. Muchos artículos no abordan los estudios microbiológicos, que serían de suma importancia para determinar la calidad de los huevos analizados.

Palabras clave: Calidad; Seguridad alimenticia; Condiciones higiénico-sanitarias.

\section{Introdução}

O Brasil vive um momento de alta dos preços dos alimentos, segundo dados do Instituto de Pesquisa Econômica e Aplicada (Ipea), o grande responsável pela inflação dos mais pobres no mês de outubro de 2020 foi o preço dos alimentos, sendo responsável por $60 \%$ do total da inflação para essa parcela da população. Dentre os gêneros alimentícios consumidos pelo brasileiro, as carnes já vinham sofrendo aumento de preço ao longo dos anos, chegando a um aumento de 6,54 \% no seu valor no mês de novembro de 2020 (Ibge, 2020). Isso demonstra o quanto a alimentação está consumindo grande parte do orçamento da população brasileira, principalmente a mais pobre.

Portanto, no contexto de aumento do preço da carne e aprofundamento da crise econômica ocasionada pela pandemia do coronavírus, projeções da Associação Brasileira de Proteína Animal (Abpa) apontam um aumento de 6,0 \% do consumo de ovos em 2021 com um consumo per capita de 265 unidades.

Como alternativa à carne no cardápio das famílias menos abastadas, os ovos apresentam-se como uma opção de alimento com preço mais acessível e com alto valor nutricional. Devido a seu conteúdo líquido completo, os ovos são considerados uma excelente fonte de nutrientes para o ser humano. A clara é constituída basicamente de proteínas, sendo a ovoalbumina a proteína majoritária, contando ainda com a presença de alguns minerais como potássio e sódio. A gema é essencialmente uma emulsão de gordura em água onde $64 \%$ dos ácidos graxos são insaturados e os elementos minerais mais abundantes são cálcio, potássio e fósforo, conta ainda com vitaminas, sendo principalmente a vitamina A e o ácido pantotênico (Ordóñez, 2005).

Com relação a sua qualidade e conservação, a casca do ovo exerce papel importante na conservação interna pois é constituída por poros que são preenchidos com fibras de natureza proteica que evitam a entrada de microrganismos. Porém, essas barreiras são temporárias e não impedem que as hifas fúngicas penetrem no interior da casca. Com o envelhecimento dos ovos ocorrem alterações nessas barreiras antimicrobianas naturais, deixando-os mais vulneráveis ao ataque microbiano (Pires et al., 2015).

A contaminação dos ovos pode ocorrer ainda dentro do trato reprodutor da galinha, antes mesmo da formação da casca, gerando ovos já contaminados (transmissão vertical). Ou os ovos podem ser contaminados após a postura. A Salmonella, por exemplo, pode penetrar na casca do ovo logo após a postura (contaminação horizontal) (Pires et al., 2015).

Contudo, estudos demonstram que muitas vezes a microbiota do oviduto de aves sadias difere da encontrada em ovos comercializados. Isso sugere que os ovos são contaminados pelo ambiente externo em contato com excreções das aves, e ou no processo de manipulação, armazenamento e comercialização inadequados permitindo a proliferação microbiana no alimento (Santos et al., 2017).

Após penetrar pelos poros na casca e ultrapassar os mecanismos naturais de proteção dos ovos, os microrganismos como bactérias e bolores chegam à gema causando mudanças internas e tornando o alimento impróprio para o consumo. A microbiota dos ovos é bem diversa podendo ser encontrados: bactérias (Salmonella spp., E. coli, Staphylococci, Streptococci, 
Mycobacterium avium, Campylobacter spp., Mycoplasmas, M. gallisepticum, M. synoviae, Chlamydia, C. psittaci), vírus (Retroviridae, Oncovirinae, Vírus da retículoendoteliose, Picornaviridae, Reoviridae, Adenovírus, Orthomyxoviridae, Circoviridae) e fungos (Aspergillus fumigatus e organismos esporulados) (Pires et al., 2015).

Ovos quando armazenados em condições inadequadas, consumidos in natura e fora do prazo de validade apresentam sérios riscos à saúde pública. A proliferação no alimento de microrganismos como Salmonella sp., Staphylococcus aureus e coliformes é responsável por surtos de infecções e intoxicações gastrointestinais. Para que se evite o risco faz-se necessário um processo de manipulação e armazenamento adequado, desde a saída da granja até a chegada dos ovos na mesa do consumidor (Netto et al., 2018).

Sendo, portanto, o ovo uma alternativa barata e de consumo essencial para muitas famílias, faz-se necessário o conhecimento e identificação das condições higienicossanitárias da comercialização desse alimento. Sabe-se que um alimento para ter seu devido potencial nutricional e não oferecer riscos à saúde deve ser conservado e manipulado em condições adequadas para então não ser fonte de doenças transmitidas por alimentos (Netto et al., 2018).

Assim, este estudo faz um levantamento de artigos que discutem as condições higienicossanitárias de ovos comercializados em diferentes cidades brasileiras, com intuito de identificar a qualidade dos ovos comercializados.

\section{Metodologia}

Para esse estudo realizou-se uma pesquisa de natureza exploratória qualitativa do tema. O objetivo fundamental de uma pesquisa exploratória é o de descrever ou caracterizar a natureza das variáveis que se deseja conhecer (Koche, 2011). Nesse caso, deseja-se explorar e conhecer as principais publicações e resultados sobre a qualidade higiênicossanitária de ovos comercializados em diferentes cidades do Brasil. Assim, para elaboração desse artigo de revisão foi realizada uma pesquisa em livros, notícias e artigos científicos que trouxessem conceitos e estudos relevantes à construção do trabalho. Quanto ao uso de artigos científicos fez-se a seleção dos mais relevantes dentro dos últimos 6 anos e que abordassem o tema em diferentes cidades/regiões do Brasil. A busca dos artigos foi feita através dos sites SciELO e Google Acadêmico utilizando os termos: "ovos", "qualidade higienicossanitaria".

\section{Resultados e Discussão}

Como resultado da pesquisa selecionou-se 14 artigos, entre os anos de 2015 a 2020. Dos 14 artigos selecionados: 3 são do sul do Brasil (Santa Catarina e Rio Grande do Sul), 4 são da região sudeste (Rio de Janeiro, São Paulo e Minas Gerais), 1 da região norte (Amazonas), 4 são da região nordeste (Paraíba, Pernambuco, Bahia e Maranhão), 1 da região centro-oeste (Goiás) e 1 artigo realizou o estudo em três estados diferentes (Rio Grande do Sul, Mato Grosso e Amazonas).

Os artigos foram organizados cronologicamente no Quadro 1, especificando os objetivos e principais resultados encontrados pelos autores. A análise e síntese dos resultados foi relatada de forma descritiva e resumida, com os pontos mais importantes dos estudos, possibilitando reunir o conhecimento sobre o tema explorado na revisão. 
Quadro 1 - Apresentação da síntese dos principais artigos encontrados na pesquisa.

\begin{tabular}{|c|c|c|}
\hline Autores & Objetivos & Resultados \\
\hline $\begin{array}{l}\text { BOIAGO } \text { et al. } \\
\text { (2015) }\end{array}$ & $\begin{array}{l}\text { Avaliar as características qualitativas de ovos comerciais } \\
\text { marrons tipo grande comercializados no município de chapecó - } \\
\text { sc nos períodos de inverno e verão. }\end{array}$ & $\begin{array}{l}\text { O estudo demonstrou que os ovos comercializados no período do inverno tiveram maiores valores de unidade Hugh e índice de gema, enquanto } \\
\text { que os comercializados no verão apresentaram valores maiores para pH da gema e do albúmen. }\end{array}$ \\
\hline $\begin{array}{l}\text { FERNANDES } e t \\
a l .(2015)\end{array}$ & $\begin{array}{l}\text { Identificar a qualidade interna de ovos brancos e vermelhos, } \\
\text { comercializados durante o inverno e o verão, no estado de são } \\
\text { paulo. }\end{array}$ & $\begin{array}{l}\text { Os ovos comercializados no vale doribeira, estado de são paulo, apresentam baixa qualidade interna e, portanto, são impróprios ao consumo e à } \\
\text { industrialização, tanto no inverno como no verão, para ovos brancos e vermelhos. }\end{array}$ \\
\hline $\begin{array}{l}\text { ROSSI \& BAMPI } \\
(2015)\end{array}$ & $\begin{array}{l}\text { Determinar a qualidade microbiológica de produtos de origem } \\
\text { animal (leite, carne e ovos) produzidos e comercializados na } \\
\text { microrregião oeste e meio oeste de santa catarina. }\end{array}$ & $\begin{array}{l}\text { Foram avaliadas } 39 \text { amostras de ovos in natura e } 4 \text { amostras de ovos de codorna em conserva. Todas as amostras apresentaram resultados } \\
\text { negativos para os microrganismos em estudo (salmonella spp., staphylococcus Coagulase Positiva E coliformes Termotolerantes). Sendo assim, } \\
100 \% \text { das amostras avaliadas atenderam a legislação. }\end{array}$ \\
\hline $\begin{array}{ll}\text { SILVA } & \text { FILHO } \\
\text { (2015) } & \end{array}$ & $\begin{array}{l}\text { Avaliar a qualidade de ovos produzidos em sistemas } \\
\text { convencionais e alternativos comercializados no município de } \\
\text { Seropédica (RJ). }\end{array}$ & $\begin{array}{l}\text { A grande maioria dos ovos convencionais e alternativos comercializados no município de Seropédica apresentou padrão de qualidade dentro do } \\
\text { esperado para ovos frescos. }\end{array}$ \\
\hline $\begin{array}{l}\text { WOLSCHICK \& } \\
\text { BOSCO (2015) }\end{array}$ & $\begin{array}{l}\text { O objetivo do trabalho foi analisar, por meio de levantamento de } \\
\text { dados, a prevalência de salmonella spp. Em ovos produzidos em } \\
\text { granjas do Rio Grande do Sul e comercializados no estado nos } \\
\text { anos de } 2010 \text { a } 2014 .\end{array}$ & $\begin{array}{l}\text { Das } 1.188 \text { amostras analisadas para verificar a prevalência de salmonella spp. Em ovos produzidos em granjas do RS e comercializados no estado } \\
\text { nos anos de } 2010 \text { a } 2014 \text {, apenas } 2,36 \% \text { estavam contaminadas. É importante ressaltar o controle de qualidade que hoje é aplicado na produção } \\
\text { dos ovos, fazendo com que haja segurança em seu consumo. }\end{array}$ \\
\hline $\begin{array}{l}\text { COSTA } \text { et } \quad \text { al. } \\
(2016)\end{array}$ & $\begin{array}{l}\text { Estudar a presença de salmonella spp. No conteúdo de ovos } \\
\text { lavados e não lavados do município de Parintins-AM em cultivos } \\
\text { de } 24 \text { e } 48 \mathrm{~h} \text {. }\end{array}$ & $\begin{array}{l}\text { Segundo o estudo, } 86,7 \% \text { das amostras apresentaram falha na integridade da casca e } 13,3 \% \text { dos ovos mostravam-se trincados. Quanto à limpeza } \\
40 \% \text { encontram-se aparentemente sujos e } 60,0 \% \text { aparentemente limpos. Verificou-se a diminuição de salmonella spp. No conteúdo de ovos } \\
\text { lavados, o mesmo foi observado nas categorias de refrigeração e limpeza, não se observou diferença relacionada à integridade do ovo. Quando } \\
\text { observado para } e \text {. Coli, verificou-se que não houve diferenças em ovos lavados quando comparados com os não lavados assim como nas categorias } \\
\text { de refrigeração, integridade e limpeza. }\end{array}$ \\
\hline $\begin{array}{lll}\text { LEITE } & \text { et } & \text { al. } \\
(2016) & & \end{array}$ & $\begin{array}{l}\text { Avaliou a qualidade microbiológica de ovos de galinhas caipira } \\
\text { produzidos e comercializados por um determinado abatedouro } \\
\text { no interior da Paraíba (PB). }\end{array}$ & $\begin{array}{l}\text { Foi encontrado baixo índice de coliformes termotolerantes nas amostras analisadas, julgando que a operação de manuseio dos ovos de galinhas } \\
\text { caipira realizadas pelo abatedouro são eficientes. Sendo também justificada à ausência de salmonella sp., ao fato que a maioria dos ovos são } \\
\text { estéreis internamente, logo após a postura. }\end{array}$ \\
\hline $\begin{array}{l}\text { SANTOS et al. } \\
(2017)\end{array}$ & $\begin{array}{l}\text { Analisou os aspectos relacionados à qualidade externa e interna } \\
\text { dos ovos produzidos em regiões do Rio Grande do Sul (RS), } \\
\text { Mato Grosso (MT) e Amazonas (am) comercializados em quatro } \\
\text { regiões no município de manaus/am. }\end{array}$ & $\begin{array}{l}\text { Quanto à qualidade externa, os ovos produzidos no Amazonas (AM) tiveram os maiores percentuais de sujidades e trincas. Houve prevalência de } \\
\text { fungos em } 57,8 \% \text { das amostras de ovos analisadas, sendo a maioria do rs. Segundo o autor, a razão deve-se provavelmente à oscilação de } \\
\text { temperatura no transporte. Já para os padrões internos, não houve diferença entre os ovos produzidos em diferentes estados, exceto a cor da gema. }\end{array}$ \\
\hline
\end{tabular}




\begin{tabular}{|c|c|}
\hline $\begin{array}{l}\text { FERREIRA et al. } \\
\text { (2017) }\end{array}$ & $\begin{array}{l}\text { Comparou a qualidade física de ovos do tipo caipira e de granja } \\
\text { produzidos em patos de minas e Uberlândia - Mg, durante o } \\
\text { armazenamento de } 11 \text { dias a temperatura ambiente }\left(25^{\circ} \mathrm{c}\right) \text {. }\end{array}$ \\
\hline LIMA et al. (2018) & $\begin{array}{l}\text { Avaliou o perfil microbiológico e a qualidade higiênicossanitária } \\
\text { de ovos comercializados em feiras livres e mercados de seis } \\
\text { municípios do recôncavo da Bahia e verificou se há correlação } \\
\text { entre os achados microbiológicos e as condições de } \\
\text { comercialização. }\end{array}$ \\
\hline $\begin{array}{l}\text { MENDONÇA et } \\
\text { al. (2019) }\end{array}$ & $\begin{array}{l}\text { Avaliar a padronização e qualidade interna e externa de ovos } \\
\text { caipiras comercializados em feira livre no município de Vitória } \\
\text { de Santo Antão-PE. }\end{array}$ \\
\hline $\begin{array}{l}\text { NETTO et al. } \\
(2019)\end{array}$ & $\begin{array}{l}\text { Analisar a ocorrência de microrganismos na casca e conteúdo } \\
\text { interno de ovos in natura comerciais, higienizados com cloro e } \\
\text { ácido peracético em diferentes concentrações, na cidade de } \\
\text { Valença, RJ. }\end{array}$ \\
\hline $\begin{array}{l}\text { SANTOS et al. } \\
\text { (2019) }\end{array}$ & $\begin{array}{l}\text { Caracterizou a qualidade externa dos ovos comercializados em } \\
\text { supermercados do município de Morrinhos - GO, por meio de } \\
\text { parâmetros visuais e passíveis de identificação pelo consumidor. }\end{array}$ \\
\hline $\begin{array}{l}\text { RUMÃO et al. } \\
(2020)\end{array}$ & $\begin{array}{l}\text { Avaliou a qualidade microbiológica de ovos in natura de } \\
\text { diferentes estabelecimentos comerciais da região metropolitana } \\
\text { de São Luís, MA. }\end{array}$ \\
\hline
\end{tabular}
Notou-se através do estudo, que as principais diferenças visuais entre os ovos, foram o tamanho, o aspecto da casca e a massa, fato atribuído à forma de criação e manejo. As diferenças encontradas nas características físicas dos ovos de granja e do tipo caipira são relativas às proporções de gema e de albúmen dos mesmos. O desempenho das amostras foi semelhante, evidenciando que a degradação dos ovos sofre maior influência das condições de armazenagem do que em relação à origem dos ovos. Contudo, devido alguns aspectos, como a umidade da gema, ovos provenientes de poedeiras do tipo caipira conservaram mais a qualidade em temperatura ambiente do que os ovos de poedeiras de granja nas mesmas condições.

As condições higienicossanitárias foram analisadas por meio de uma lista de verificação. Foi realizada a quantificação de coliformes totais e escherichia coli, mesófilos, psicotróficos, bolores e leveduras e análise da presença de salmonella sp. $\mathrm{Na}$ análise observacional verificou-se que $91,67 \%$ e $68,53 \%$ das amostras de feiras livres e mercados, respectivamente, não estavam conforme os parâmetros exigidos pelas legislações. Quanto ao perfil microbiológico, não houve diferença significativa entre feira livres e mercado. A análise de salmonella spp. Apontou apenas Uma amostra fora dos padrões vigentes. Observou-se correlação entre a contagem de microrganismos e as varí́veis da lista de verificação, sendo que as amostras que apresentavam não conformidade obtiveram maiores concentrações de coliformes totais e escherichia coli.

Os ovos analisados apresentaram boa qualidade independentemente do local de aquisição. Apenas os ovos da banca d apresentaram peso inferior Os ovos analisados apresentaram boa qualidade independentemente do local de aquisição. Apenas os ovos da banca d apresentaram peso inferior
a $45 \mathrm{~g}$, o que deve ser utilizado na indústria, conforme a legislação vigente no país. Essa variação na qualidade dos ovos em feira livre se dá pela comercialização de ovos de galinhas de idades diferentes e qualidade diversa em mesma bandeja.

Os ovos submetidos a diferentes procedimentos de sanitização apresentaram 33,3\% de coliformes totais. Os tratamentos com cloro 50 e 100 ppm foram mais eficazes na eliminação dos microrganismos mesófilos aeróbios. A utilização de apenas água mostrou-se eficaz na redução de coliformes totais e termotolerantes. Pode-se concluir que a higienização de ovos com água potável seguida da sanitização com cloro 100 ppm por 3 minutos é eficiente para a redução de microrganismos. A higienização dos ovos com ácido peracético 50 ppm apresentou redução nas populaç̃es de mesófilos, entretanto não é recomendável, devido suas dificuldades de utilização, e pelas altas concentrações serem prejudiciais à qualidade da casca. Já o conteúdo interno dos ovos foi ausente para a presença de mesófilos aeróbios, coliformes totais, coliformes termotolerantes e salmonella spp.

Os ovos comercializados em morrinhos - go estão fora do padrão de comercialização exigido pela legislação. Apresentando sujidades e trincas na casca, podendo ser um risco potencial à saúde do consumidor.

Avaliando o conteúdo interno dos ovos, foram encontrados em 55\% das amostras a presença de microrganismos aeróbios mesófilos e em $25 \%$ a presença staphylococcus spp., sendo o mercado público o que apresentou o menor nível de contaminação, provavelmente devido a rápida comercialização desses produtos. Para bolores e leveduras, 52,5\% das amostras apresentaram contaminação. Além disso, a avaliação das condições internas dos ovos constatou a contaminação por coliformes com $12,5 \%$ das amostras positivas. A presença de coliformes ermotolerantes foi confirmada em 5\% das amostras de supermercado atacadista. A presença de salmonella spp. Foi confirmada em $12.5 \%$ higienicossanitária do produto. Portanto, do total de 40 amostras avaliadas, 12,5\% encontraram-se com qualidade microbiológica insatisfatória.

Fonte: Autores (2021) 
Os artigos apresentados permitem obter um panorama geral dos diversos parâmetros utilizados para determinar a qualidade de ovos, desde suas características físico-químicas, microbiológicas e aspectos visuais. Fica evidente que os artigos apresentam uma diversidade de resultados: desde ovos dentro dos padrões, até ovos contaminados. Nota-se como as condições de manuseio, armazenamento e conservação são essenciais para a qualidade dos ovos.

Regiões como o centro-oeste e norte têm poucos estudos recentes publicados sobre o tema, o que demonstra a necessidade de mais publicações para essas regiões. Para os estados do Amazonas e Goiás, os estudos apresentados mostram qualidade insatisfatória com presença de trincas e sujidades na casca, sendo, portanto, os estados mais críticos pela análise dos artigos apresentados. Dentre todos os artigos selecionados, apenas 4 puderam demonstrar nos seus resultados qualidade insatisfatória dos ovos analisados. Mesmo com a minoria dos resultados para qualidade insatisfatória, considerando as características físico-químicas e microbiológicas dos ovos e seu grande consumo, não se deve desconsiderar os riscos à população.

Para possibilitar conhecer melhor a qualidade dos ovos, o ideal seria mais estudos que envolvessem a avaliação da qualidade microbiológica interna. Isso permitiria perceber se há contaminação dos ovos por microrganismos como salmonella sp., staphylococcus aureus e coliformes que são grandes responsáveis por surtos de infecções e intoxicações gastrointestinais.

\section{Conclusão}

O conhecimento da qualidade dos ovos comercializados em diversas cidades brasileiras permite identificar falhas nas condições higiênicossanitárias do processo de comercialização, fornecendo embasamento teórico para discutir melhorias da qualidade neste processo. Percebe-se que há diferenças de qualidade entre os ovos estudados e que muitos artigos não abordam estudos microbiológicos, o que seria de extrema importância para determinar a qualidade interna dos ovos analisados. Sabemos que há perigo no consumo de ovos comercializados em condições inadequadas, já que é um alimento passível de grande desenvolvimento de microbiota patogênica.

Este trabalho, exploratório e qualitativo em sua natureza, buscou reunir informações que permitissem obter um parecer sobre as condições higiênicossanitárias dos ovos comercializados em diversas cidades brasileiras. Durante o processo de pesquisa ficou evidente a carência de estudos recentes publicados sobre o tema e, principalmente, estudos que envolvam caracterização microbiológica das amostras. Assim, como proposta de estudos futuros, os autores sugerem que mais pesquisas possam ser publicadas abrangendo mais regiões do país, como o norte e centro-oeste, onde encontrou-se poucas publicações recentes.

\section{Referências}

Associação Brasileira de Proteína Animal (2021). Abpa divulga perspectivas para 2021. https://abpa-br.org/perspectivas-para-2021/.

Boiago, E. S., Dinon, A. Z., \& Boiago, M. M. (2015). Efeito do período do ano sobre a qualidade de ovos comercializados no sul do brasil. Nucleus Animalium, 7(2). 10.3738/21751463.1466.

Costa, V. R, Paiva, A. N., Berenchtein, B., Lehmkuhl, A. M. S., Santos, A. N. A., \& Molenedo, R. R. C (2016). Avaliação microbiológica em ovos comerciais lavados e não lavados. Revista Científica Avicultura e Suinocultura, 2(1), 1-10. https://www.periodicos.ufam.edu.br/index.php/RECAS/article/view/2302/pdf

Fernandes, D. P. B., Mori, C. Nazareno, A. C., Pizzolante, C. C., \& Moraes, J. E. (2015). Qualidade interna de diferentes tipos de ovos comercializados durante o inverno e o verão. Arq. Bras. Med. Vet. Zootec., 67 (4). https://doi.org/10.1590/1678-4162-7808

Ferreira, D. B. S., Fernandes, E. A., Saar, A. G. L., Moura, A. G. S., \& Lima, M. (2017). Comparação da qualidade física de ovos do tipo caipira e de granja no interior de minas gerais. XII Congresso Brasileiro de Engenharia Química em Iniciação Científica. 3263-3268. 10.5151/chemeng-cobeqic2017-405

Instituto Brasileiro de Geografia e Estatística (2020). Indicadores IBGE: sistema nacional de índices de preços ao consumidor. 19p. https://biblioteca.ibge.gov.br/visualizacao/periodicos/236/inpc_ipca_2020_nov.pdf.

Instituto Brasileiro de Geografia e Estatística (2020). Alta no preço dos alimentos representam $60 \%$ da inflação dos mais pobres em outubro. https://www.ipea.gov.br/portal/index.php?option=com_content\&view=article\&id=37070\&catid=131.

Koche, J. C. (2011). Fundamentos de metodologia científica. Petrópolis: Vozes. http://www.brunovivas.com/wp-content/uploads/sites/10/2018/07/K\%C 3\%B6che-Jos\%C3\%A9-Carlos0D0AFundamentos-de-metodologia-cient\%C3\%ADfica-_-teoria-da0D0Aci\%C3\%AAncia-e-inicia\%C3\%A7\%C3\%A3o-\%C3\% A0-pesquisa.pdfhttps://repositorio.ufsm.br/bitstream/handle/1/15824/Lic_Computacao_Metodologia-Pesquisa-Cientifica.pdf?sequence=1 
Leite, D. D. F., Cavalcanti, M. T., Albuquerque, A. P., Pereira, E. V. S., \& Florentino, E. R. (2016). Qualidade microbiológica de ovos de galinhas caipira comercializados no interior da Paraíba. AGROTEC - Revista Agropecuária Técnica, 37(1), 32-35. 10.25066/agrotec.v37i1.29282.

Lima, W. K. S., Barros, L. S. S., Silva, R. M., Deus, T. B., Lima, D. V. \& Silva, A. S. (2018). Condições higiênico-sanitárias de ovos comercializados em feiras livres e mercados. Revista Brasileira de Higiene e Sanidade Animal, 12(3), $280-294 . \quad$ http://www.higieneanimal.ufc.br/seer/ind ex.php/higieneanimal/article/view/455

Mendonça, T. H. C., Soares, A. R. S., Silva, J. R., Souza, M. S., Silva Júnior, A. F., \& Silva, A. R. G. (2019). Padronização e qualidade de ovos caipiras comercializados em feira livre no município de Vitória de Santo Antão (Pernambuco - Brasil). Revista Brasileira de Meio Ambiente, 7(3), 38-47. 10.5281/zenodo. 3575265

Netto, L. B. C., Silva, L. M. \& Xavier, M. M. B. B. S. (2018). Qualidade e rotulagem de ovos comercializados no município de Valença - RJ. PUBVET Medicina Veterinária e Zootecnia, 12 (9),1-9. https://doi.org/10.31533/pubvet.v12n9

Ordónez, J. A. (2005). Ovos e produtos derivados. In: Tecnologia de Alimentos. Alimentos de Origem Animal. Artmed, 269-279.

Pires, M. F., Pires, S. F., Andrade, C. L., Carvalho, D. P. \& Marques, M. R. (2015). Aspectos sobre a contaminação de ovos comerciais. Nutritime, 12(5). https://www.nutritime.com.br/arquivos_internos/artigos/319_-_4209-4215_-_NRE_12-5_set-out_2015.pdf

Rossi, P. \& Bampi, G. B. (2015). Qualidade microbiológica de produtos de origem animal produzidos e comercializados no Oeste Catarinense. Segurança Alimentar e Nutricional, Campinas, 22 (2), 748-747. https://doi.org/10.20396/san.v22i2.8642505

Rumão, J. da S., Brito, D. A. P., Reinehr, C. O., Conceição, A. O. \& Frazão, R. M. (2020). Salmonella spp. and microbial quality indicators in eggs marketed in the Metropolitan Region of São Luís, Maranhão, Brasil. Research, Society and Development, 9(8). https://doi.org/10.33448/rsd-v9i8.6175

Santos, F. F. dos, Rosemberg, R. L., Lima, S. P. C. H. \& Oliveira, J. B. (2017). Avaliação da qualidade de ovos comercializados no município de Manaus- AM Higiene Alimentar, 31 (264/265),109-1141. https://docs.bvsalud.org/biblioref/2017/04/833116/264-265-sitecompressed-109-114.pdf\#: :text=Os\% 20ovos\%20d e\% 2 0consumo\%20comercializados,no\%20munic\%C3\%ADpio\%20de\%20Manaus\%2C\%20AM.

Santos, T. L. S., Souza, C. M., Fernandes, A. P. S., Oliveira, E. M. B., Dantas, F. H. S. \& Melo, A. G. (2019). Caracterização de ovos de galinha comercializados em supermercados do município de Morrinhos - GO. In: $29^{\circ}$ CONGRESSO BRASILEIRO DE ZOOTECNIA, 2019, Uberaba. Anais eletrônicos... Campinas, Galoá. https://proceedings.science/zootec-2019/papers/caracterizacao-de-ovos-de-galinha-comercializados-em-supermercados-do-municipio-de-morrinhos--go

Santos Neto, J. P., Oliveira, C. C., Silva, P., A., Fonseca, C. R. \& Ciabotti, E. D. (2019). Ocorrência de aeróbios mesófilos, coliformes e salmonella sp., em ovos comerciais higienizados por diferentes métodos. Revista Craibeiras de Agroecologia, 4(1). https://www.seer.ufal.br/index.php/era/article/view/7717

Silva Filho, C. A., Calixto, L. F. L., Lemos, M. J., Reis, T. L. \& Macedo, K. B. R. (2015). Qualidade de ovos convencionais e alternativos comercializados na região de Seropédica (RJ). Revista Acadêmica Ciência Animal, 12 (3). http://dx.doi.org/10.7213/academica.13.FC.AO19

Wolschick, J. \& Bosco, S. M. D. (2015). Prevalência de Salmonella spp. em ovos de galinha de granja em casca produzidos e comercializados no Rio Grande do Sul. Revista Destaques Acadêmicos, 7(3), 182-187. http://www.univates.br/revistas/index.php/destaques/article/view/493/0 